\title{
Agent-based modelling
}

\author{
Maja Schlüter, ${ }^{1}$ Emilie Lindkvist, ${ }^{1}$ \\ Nanda Wijermans ${ }^{1}$ and Gary Polhill ${ }^{2}$
}

${ }^{1}$ STOCKHOLM RESILIENCE CENTRE, STOCKHOLM UNIVERSITY, STOCKHOLM, SWEDEN

${ }^{2}$ THE JAMES HUTTON INSTITUTE, ABERDEEN, UK

\section{Key methods discussed in this chapter}

Agent-based modelling

\section{Connections to other chapters}

This method connects to participatory modelling (Chapter 8), as agent-based models are often developed and/or used in participatory processes. Agent-based models can also be used to support scenario development (Chapter 11) and futures analysis (Chapter 10), or to develop serious games (Chapter 12). The design and parameterisation of an agent-based model can be informed by knowledge and data collected through systems scoping (Chapter 5), interviews and surveys (Chapter 7), or ecological field data collection (Chapter 6). Agent-based models are generally analysed by running many simulations which generate synthetic data that can then be processed with statistical methods (Chapter 18). Agent-based models can also be combined with dynamical systems modelling (Chapter 26) in hybrid models.

\section{Introduction}

Agent-based modelling is a computational method that emerged in the early 1970s simultaneously in several fields, particularly in complexity, economic, sociological and computer sciences (distributed artificial intelligence) (Hare and Deadman 2004). An agent-based model (often referred to as $\mathrm{ABM}$ ) is a computer program composed of autonomous agents, i.e. agents whose behaviour is not centrally controlled, who are diverse and interact with one another and their environment. The program is simulated over time: at each time step or event, agents take decisions and act based on their internal state and/or in response or anticipation of other agents' behaviours or changes in the environment. The microlevel actions and interactions of many agents give rise to macrolevel patterns and dynamics which are typically the focus of analysis. The micro- and macrolevel outcomes of individual actions can modify the internal state of the agents and prompt them to change their behaviour in the subsequent time steps. The agents thus adapt to the contexts they jointly create, which is a key 


\begin{tabular}{|c|c|}
\hline \multicolumn{2}{|c|}{ SUMMARY TABLE: AGENT-BASED MODELLING } \\
\hline DISCIPLINARY BACKGROUND & KNOWLEDGE TYPE \\
\hline $\begin{array}{l}\text { The methods in this chapter are derived } \\
\text { from or have most commonly been used in: } \\
\text { Complexity Science, Computer Science/ } \\
\text { Distributed Artificial Intelligence }\end{array}$ & $\begin{array}{l}\text { The methods in this chapter are primarily } \\
\text { used to generate the following types of } \\
\text { knowledge: } \\
\text { - Descriptive } \\
\text { - Exploratory } \\
\text { - Explanatory }\end{array}$ \\
\hline RESEARCH APPROACH & PURPOSE OF METHOD \\
\hline $\begin{array}{l}\text { The methods in this chapter originate } \\
\text { from or most commonly adopt the } \\
\text { following research approaches: } \\
\text { - Analytical/objective } \\
\text { - Collaborative/process }\end{array}$ & $\begin{array}{l}\text { The most common purposes of using the } \\
\text { methods in this chapter are: } \\
\text { - System understanding } \\
\text { - Stakeholder engagement and } \\
\text { co-production } \\
\text { - Policy/decision support }\end{array}$ \\
\hline TEMPORAL DIMENSION & SYSTEMIC FEATURES AND PROCESSES \\
\hline $\begin{array}{l}\text { The methods in this chapter are most } \\
\text { commonly applied to the following } \\
\text { temporal dimensions: } \\
\text { - Present (typically within the last } \\
5-10 \text { years) } \\
\text { - Recent past (post-1700s) } \\
\text { - Pre-industrial revolution (pre-1700s) } \\
\text { - Future }\end{array}$ & \multirow{3}{*}{$\begin{array}{l}\text { While most methods can do many } \\
\text { things, the methods in this chapter are } \\
\text { particularly good (i.e. go-to methods) for } \\
\text { addressing the following: } \\
\text { - SES components and linkages } \\
\text { - Diversity } \\
\text { - Multiple scales and levels or } \\
\text { cross-level interactions } \\
\text { - Social-ecological interactions } \\
\text { over time } \\
\text { - Path dependency } \\
\text { - Adaptation and self-organisation } \\
\text { - Evaluating policy options } \\
\text { - Exploring uncertainty }\end{array}$} \\
\hline SPATIAL DIMENSION & \\
\hline $\begin{array}{l}\text { The methods in this chapter are primarily } \\
\text { either or both: } \\
\text { - Non-spatial } \\
\text { - Explicitly spatial } \\
\text { The methods in this chapter are most } \\
\text { commonly applied at the following } \\
\text { spatial scales: } \\
\text { - Local } \\
\text { - Regional }\end{array}$ & \\
\hline
\end{tabular}


characteristic of complex adaptive systems. The evolution of the system over time can result in system-level outcomes that stabilise in some form of dynamic equilibrium or continuously change indefinitely in a chaotic or a regularly fluctuating manner.

The conceptual foundation of agent-based modelling is the theory of complex adaptive systems (Arthur, Durlauf, and Lane 1997). Agent-based modelling is one of the key methods to study emergent phenomena, i.e. system-level patterns or behaviours that cannot be explained by the individual components alone, but arise from interactions among individual agents who adapt and learn about their environment. In that sense, agent-based modelling supports the development of generative explanations: explanations that specify the microlevel interactions of heterogeneous agents that bring about a macrolevel phenomenon of interest (Epstein 2006). While agent-based models have been primarily used to study the emergence of system-level outcomes from microlevel interactions of agents, ultimately both system-level and microlevel behaviour matter as they influence each other.

Agent-based models have been used to represent and study many complex adaptive systems, from immune systems, social systems and ecosystems to social-ecological systems (SES). In models of SES, the agents often represent individual or collective actors (e.g. fishers, households, organisations) or biological organisms (e.g. fish, fish populations or livestock). The social environment comprises social structures (e.g. social networks or neighbourhoods). The biophysical environment represents natural resources or ecosystems that are used or affected by the behaviour of the agents (e.g. patches of land, fishing areas, forest patches or landscapes). The agents are characterised by their properties and behaviours, which may vary among agent types (e.g. fishers who use different fishing styles) or within one type (e.g. a farmer with more or less wealth). The agents are often also characterised by their location in space or in a social or ecological network.

One of the first and most well-known agent-based models of social phenomena was Sakoda-Schelling's model of segregation (Sakoda 1971; Schelling 1971). One of the earliest applications of agent-based modelling to SES is Lansing and Kremer's model of the emergence of patterns of rice-paddy irrigation in Bali (Lansing and Kremer 1993) and the model of a fishery developed by Bousquet et al. (1993). The use of agent-based modelling in support of participatory processes has a long tradition in natural resource management (Bousquet et al. 1999; Bousquet and Le Page 2004). As agent-based modelling has gained momentum in the last decades, it has been applied in more diverse fields, including sociology, psychology, political science, economics, philosophy, ecology, natural resource use, land-system science and SES research (Schulze et al. 2017; Gotts et al. 2018). Agent-based models can be developed for many different purposes, ranging from exploring, understanding, explaining, predicting, communicating or illustrating to an analogy or a mediator for social interaction between diverse stakeholders or disciplinary researchers (Edmonds et al. 2019).

\section{SES problems and questions}

Several characteristics of agent-based modelling make it an interesting and important method for SES research: (a) its focus on the change of an SES over time from mutual adaptations of agents and their environments, (b) its ability to generate emergent system-level outcomes from microlevel interactions and macrolevel feedbacks, thus enabling the study of an SES as a complex adaptive system, (c) its ability to represent the diversity and heterogeneity of human and non-human actors as well as the spatial characteristics of an SES, and (d) its capacity to serve as a virtual laboratory in which researchers and stakeholders can experiment with an SES to explore possible consequences of interventions or identify and test causal relationships that underlie an emergent phenomenon. 
Agent-based modelling is applied to both theoretical and empirical questions. Theoretical models can be conceptual or stylised with the aim to explore or understand key mechanisms that determine the behaviour of an SES. Empirical models can be built for a particular system (e.g. a fishery or a landscape) using data and knowledge collected in the field through empirical methods (see Chapters 5 and 7) and/or participatory processes (see Chapter 13) (Janssen and Ostrom 2006; Smajgl and Barreteau 2014). The degree of realism of an agent-based model is tied to the purpose of the model. Agent-based models of SES are often developed for one of the following purposes: (a) to explore or explain the emergence of social-ecological outcomes and understand the evolution of the SES over time, (b) to assess the impact of a new policy or disturbance on an SES that is understood as a complex adaptive system, including potential unintended consequences, and (c) to support a participatory process that aims to enhance problem understanding and co-develop problem solutions.

Typical questions related to enhancing the understanding of emergent outcomes and system change over time include:

- What land-use patterns emerge from land-use choices of farmers, as influenced by formal or informal institutions, social networks or the behaviour of other farmers? (Parker and Meretsky 2004; Manson et al. 2016)

- How robust is cooperation for shared natural resource use to environmental variability? (Schlüter, Tavoni, and Levin 2016)

- What are the implications of pastoralist behavioural diversity for the sustainability of a rangeland? (Dressler et al. 2018)

- How important is actors' diversity for the resilience of SES to global change? (GrêtRegamey, Huber, and Huber 2019)

Typical questions related to the use of agent-based models for policy assessment include:

- How will a fuel policy affect poverty patterns and future land use and land cover in a region in Indonesia? (Smajgl and Bohensky 2011)

- What are the benefits of spatial cooperative harvesting schemes in a marine fishery? (Gutierrez et al. 2017)

- How can we design policies that incentivise farmers to conserve biodiversity? (Gimona and Polhill 2011; Polhill, Gimona, and Gotts 2013)

The aim of the use of agent-based modelling in participatory processes is to disclose and discuss different interpretations of the system and stakeholder objectives, develop a shared system understanding, support joint deliberation and social learning, and develop management solutions (see also Chapter 13). Joint model development requires stakeholders to make their assumptions explicit and stimulates discussions about what is important. The process of specifying a model, particularly in an inter- or transdisciplinary team or in participatory processes with stakeholders, is often as insightful as the model outcomes themselves and can lead to new questions for further research. Applications of agent-based modelling in participatory processes include:

- The use of an agent-based model in support of a process to resolve a conflict over sharing water resources between two communities along a river (Gurung, Bousquet, and Trébuil 2006)

- The use of an agent-based model in a participatory process for analysing a fishery and developing a management plan (Worrapimphong et al. 2010) 
Recent work has highlighted the potential of agent-based modelling for studying systemic change such as regime shifts (Filatova, Polhill, and Van Ewijk 2016; Polhill et al. 2016). Land-system science has made extensive use of the potential of agent-based modelling to represent interactions among actors in space, e.g. a farmer making a decision based on her neighbour's actions (Happe, Kellermann, and Balmann 2006; Bert et al. 2011; Villamor et al. 2014). Land-use agent-based models typically represent the landscape as a grid of cells with different land-use types or a spatially explicit representation from a geographic information system (Crooks, Heppenstall, and Malleson 2018). Many agent-based models in land-system science focus on land-use and land-cover change or policy scenario analysis, with a focus on explicit representation of spatial dynamics, psychologically plausible decision-making and biophysical and social interactions. Many agent-based models of natural resource management focus on the sustainable exploitation of resources such as fish (Burgess et al. 2020; Lindkvist et al. 2020), water or forests, given the diversity of resource users, social dilemmas, social interactions and the dynamics of the resource. Other areas of application of agentbased modelling are human-wildlife interactions or tourism in protected areas. Agent-based modelling has also been extensively used to study the collapse of past societies such as the Anasazi or the Maya, particularly how it may have been caused by environmental or social change (Janssen 2009; Heckbert 2013).

\section{Brief description of key methods}

The process of developing and using an agent-based model includes several steps: model design, model building, model testing, simulation experiments or scenario analysis, and communication of results. In general, the development of an agent-based model starts with identifying the purpose and research question the model should address. This guides the development of the model, particularly the selection of the agents, their behaviours and the social and ecological environments in which they (inter-)act. The assumptions underlying these choices can be: (a) based on qualitative and quantitative empirical studies of a particular place, such as a farming landscape, (b) co-developed with researchers and/or stakeholders in a participatory process, (c) based on stylised facts derived from expert knowledge and the literature, or (d) based on theory. Often a mix of sources is used because no single source provides all the understanding and evidence needed.

Once the model has been designed and implemented in computer code, the virtual SES can be simulated by running the software. After being thoroughly tested and validated, it can then be deployed to simulate different scenarios or run experiments, for instance to assess the impact of policies, changes in selected parameter values, or the presence or absence of certain processes. The simulations produce large amounts of simulated data about the model system, which are then analysed to study outcomes of interest using statistical methods or machine-learning algorithms.

Various methods can be applied to each of the steps outlined above. These include: (a) methods to collect and analyse qualitative or quantitative empirical data, elicit expert or stakeholder knowledge (Bharwani 2006), or identify theories to inform the design of the structure of the model (what to include and what not) and behavioural rules governing the agents' behaviour (Smajgl et al. 2011; Smajgl and Barreteau 2014; Schlüter et al. 2017), (b) methods to determine parameter values and assess the sensitivity of the model to parameter choices (Thiele, Kurth, and Grimm 2014), (c) methods of experimental design to develop and analyse scenarios (Lorscheid, Heine, and Meyer 2012), and (d) statistical, pattern-recognition and mathematical methods to analyse, validate and represent simulation data and outcomes 
(Lee et al. 2015; Martin and Thomas 2016; Thomas, Lloyd, and Skeldon 2016). The applicability of the different methods and the type of analysis and validation needed depend on the purpose of the model and the context of model development.

Model development is often an iterative process, looping between the design of the model and a case study or theoretical foundations. Given the interdisciplinary and complex nature of SES problems, the agent-based modelling activity is ideally embedded in a larger interdisciplinary research process where multiple methods are being combined (Schlüter, Müller, and Frank 2019; Schlüter et al. 2019). A model and its results should always be interpreted in light of the underlying assumptions, the model purpose and the intended use of the model (Schlüter, Müller, and Frank 2019). A careful process of choosing the assumptions and transparency in communicating model assumptions is thus essential (Schlüter et al. 2014; Gotts et al. 2018). The agent-based modelling community has developed several protocols to facilitate good and standardised model communication (Grimm et al. 2006; Schmolke et al. 2010; Müller et al. 2013).

Table 28.1 summarises a few of the most common uses of agent-based modelling in SES research.

Table 28.1 Summary of key applications of agent-based modelling

\begin{tabular}{|c|c|c|}
\hline Main applications & Description & References \\
\hline $\begin{array}{l}\text { Exploring emergent } \\
\text { SES outcomes and } \\
\text { dynamics }\end{array}$ & $\begin{array}{l}\text { A model is developed and used to explore } \\
\text { system-level outcomes and system } \\
\text { trajectories that emerge from interactions } \\
\text { between actors, elements of ecosystems } \\
\text { and their social and biophysical } \\
\text { environments. }\end{array}$ & $\begin{array}{l}\text { Applications to SES } \\
\text { Carpenter and Brock 2004; } \\
\text { Wilson, Yan, and Wilson 2007; } \\
\text { Evans and Kelley 2008; } \\
\text { Heckbert 2013; } \\
\text { Castilla-Rho et al. } 2017\end{array}$ \\
\hline Policy assessment & $\begin{array}{l}\text { A model is used to assess possible } \\
\text { outcomes of different policy scenarios, } \\
\text { e.g. the effect of introducing an } \\
\text { individual transferable quota on the } \\
\text { sustainability of fisheries, or of a fuel } \\
\text { subsidy on poverty. }\end{array}$ & $\begin{array}{l}\text { Applications to SES } \\
\text { Smajgl and Bohensky 2011; } \\
\text { Sun and Müller } 2013\end{array}$ \\
\hline $\begin{array}{l}\text { Assessment of } \\
\text { response of SES to } \\
\text { environmental or } \\
\text { social change }\end{array}$ & $\begin{array}{l}\text { A model is used to explore how an SES } \\
\text { may respond to environmental or social } \\
\text { change, such as climate change impacts } \\
\text { or changes in market conditions. }\end{array}$ & $\begin{array}{l}\text { Applications to SES } \\
\text { Melbourne-Thomas et al. 2011; } \\
\text { Klein, Barbier, and Watson } 2017\end{array}$ \\
\hline $\begin{array}{l}\text { Explaining emergent } \\
\text { SES phenomena }\end{array}$ & $\begin{array}{l}\text { A model is developed and used to } \\
\text { identify social-ecological mechanisms } \\
\text { that produced an observed outcome of } \\
\text { interest. }\end{array}$ & $\begin{array}{l}\text { Applications to SES } \\
\text { Schill et al. 2016; } \\
\text { Lindkvist, Basurto, and Schlüter } \\
\text { 2017; } \\
\text { Plank et al. } 2017\end{array}$ \\
\hline $\begin{array}{l}\text { As boundary object } \\
\text { in participatory } \\
\text { processes }\end{array}$ & $\begin{array}{l}\text { A model is co-developed and/or used as } \\
\text { boundary object to facilitate a process } \\
\text { of social learning and co-developing } \\
\text { solutions to problems in a particular case } \\
\text { or for integration of different (disciplinary) } \\
\text { understandings. }\end{array}$ & $\begin{array}{l}\text { Applications to SES } \\
\text { Castella, Trung, and Boissau 2005; } \\
\text { Gurung, Bousquet, and Trébuil } \\
\text { 2006; } \\
\text { Worrapimphong et al. 2010; } \\
\text { Forrester et al. } 2014\end{array}$ \\
\hline
\end{tabular}




\section{Limitations}

Agent-based models are very flexible and can incorporate many details of the real world in a disaggregate manner. This is a great advantage because important aspects of an SES, such as diversity, spatial arrangements and heterogeneity, can be represented. These aspects are usually difficult to model with aggregate approaches such as dynamical systems modelling. The realism of agent-based models also makes it easier for the modeller to communicate them to non-modellers. This flexibility, however, also poses a challenge as choices need to be made about what to include or exclude in the model. There are no general guidelines because these choices are context-specific and model-purpose-specific and influenced by the backgrounds, knowledge and experience of those involved in building the model. Including too many details or too much heterogeneity leads to very complex models that are difficult to analyse and that pose challenges for transparency and reproducibility (Kremmydas, Athanasiadis, and Rozakis 2018). Complex agent-based models of a particular SES that are developed to explore responses of the SES to interventions or other external changes, however, can still work well if they are validated with empirical data. Complex models are more problematic when the aim of the model is to explain how a specific outcome came about.

Agent-based models need to be thoroughly analysed to build confidence in the model, i.e. to ascertain that a result is not an artefact of the model structure or parameter values, to test their validity, and to assess the robustness of model results to uncertainties about the structure of the model or parameter values. A common method to deal with uncertainty of modelling choices and parameter values is to conduct sensitivity and uncertainty analyses. Uncertainty that arises from the context-dependence of human decision-making and behaviour is often modelled using stochastic variables, e.g. a behavioural choice is modelled with a certain probability. Because of the complex, multi-level and evolutionary nature of agent-based models, standard mathematical tools, such as identification of equilibrium points and stability analysis, are not applicable. Instead, model behaviour needs to be systematically explored.

Recent developments in statistical methods as well as advances in mathematical analysis or approximation of agent-based models (Martin and Thomas 2016; Thomas, Lloyd, and Skeldon 2016) can significantly enhance model analysis. At the same time, agentbased models provide the opportunity to analyse the evolution of the SES over time when it is out of equilibrium, examine the implications of random events, and study feedbacks and path dependencies. All this is difficult to do with other modelling approaches. Analysis of the transient behaviour of SES using agent-based models is a current research frontier (see Section 'New directions').

\section{Resource implications}

The most commonly used platform for developing agent-based models in ecology and SES research is NetLogo (ccl.northwestern.edu/netlogo). NetLogo is easy to learn and has a simple user interface that has made it popular for both teaching and scientific applications of agent-based modelling (see textbooks by Railsback and Grimm 2012 and Janssen 2020). There are alternative platforms (reviewed by Kravari and Bassiliades 2015), as well as the option of writing all the software to implement the simulation yourself. Most agent-based models can be run on personal computers; however, large-scale model output analyses and more complex or empirical agent-based models typically use larger machines or clusters. There is a growing repository of agent-based models of SES at comses.net. 
The development of an SES agent-based model requires programming skills and skills in identifying and synthesising knowledge and data to develop a representation of an SES that can answer a research question. The modeller will need data analysis skills to analyse large amounts of simulation data using software, such as $\mathrm{R}$, and skills to visualise the data. There are an increasing number of courses on agent-based modelling in SES or related fields that teach many of these skills. If the combination of skills seems daunting, there is the option of working in small collaborative teams to design, implement and analyse the results of agent-based models. Agentbased modelling is in any case a cross-disciplinary activity (Squazzoni 2010).

Whereas building a first prototype agent-based model can be done quickly, constructing a full model and testing and analysing it thoroughly is often time consuming. The different phases of building and using an agent-based model require different amounts of time depending on

\section{Case study 28.1: The establishment and persistence of cooperative forms of self-governance in small-scale fisheries in north-west Mexico}

This example is taken from the work of Lindkvist, Basurto and Schlüter (2017), who developed an agent-based model to study the self-governance of smallscale fisheries in north-west Mexico. The aim of this agent-based model is to explore and explain why non-cooperative forms of self-governance, such as fisher-trader relationships, dominate many small-scale fishing communities in north-west Mexico. In particular, it was developed to investigate how the heterogeneity of fishers' reliability, organisational characteristics of different self-governance forms (e.g. loyalty and trust) and the fish population, through their dynamic interactions, may explain observed differences in self-governance arrangements. The researchers developed an agent-based model of an archetypical

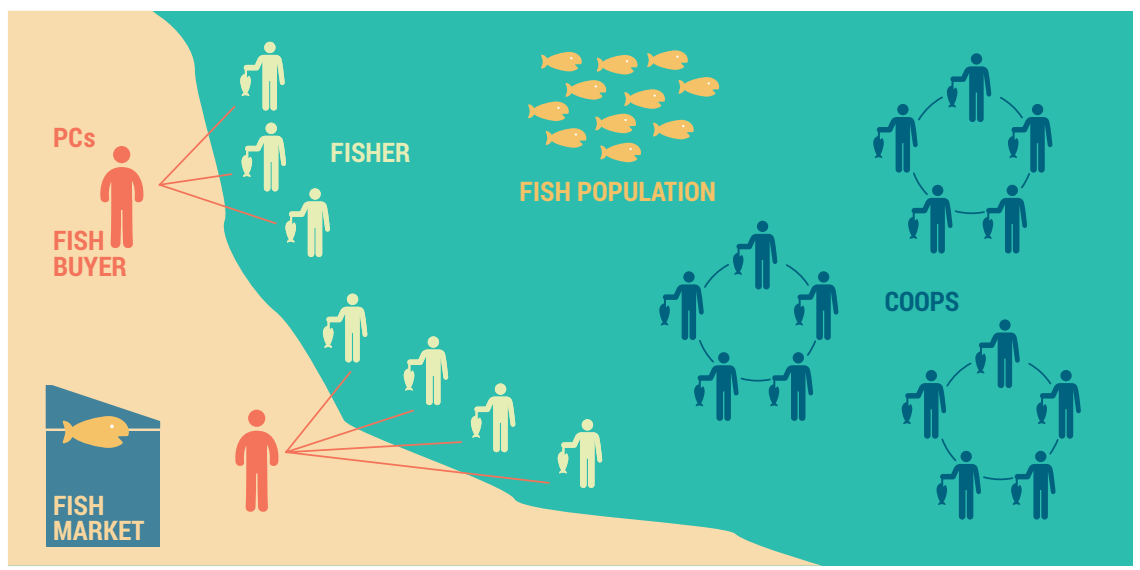

Figure 28.1 Key elements of the stylised agent-based model of a small-scale fishery (Lindkvist, Basurto, and Schlüter 2017) 
the skills of the researcher(s) and the problem at hand. The development of a research question that is suitable to be addressed with an agent-based model and the collection and synthesis of the data that will inform the model structure are often as time consuming as the programming of the model itself.

\section{New directions}

New interesting fields of application of agent-based modelling include understanding social-ecological regime shifts (Filatova, Polhill, and Van Ewijk 2016; Martin, Schlüter, and Blenckner 2020) or societal transformations (Holtz et al. 2015; Köhler et al. 2018) from a complex adaptive systems perspective. Recent agent-based modelling of regime shifts has focused on

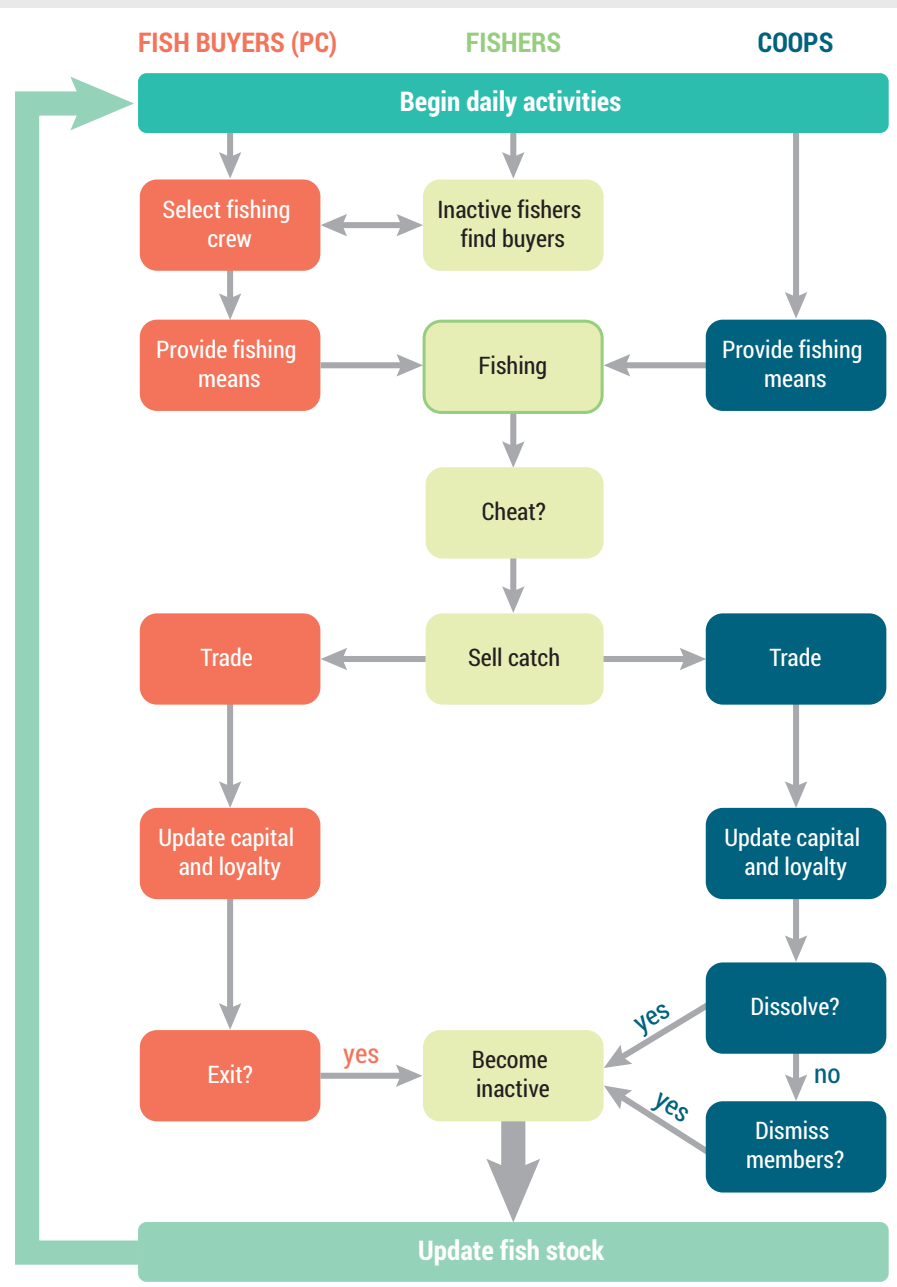

Figure 28.2 Flowchart of actions and interactions of the three key types of agents in the model (Lindkvist, Basurto, and Schlüter 2017) 
small-scale fishery with cooperative and non-cooperative self-governance forms (Figures 28.1 and 28.2). The aim of the model is to answer the research question, 'Under which conditions can cooperative forms of self-governance establish and survive?' It captures key insights and hypotheses from in-depth fieldwork in north-west Mexico about fishers' day-to-day fishing and trading, the activities of fish buyers and cooperatives, as well as factors that influence their performance (Basurto et al. 2020). It represents two ubiquitous forms of self-governance: hierarchical non-cooperative arrangements between fishers and fish buyers, such as patron-client relationships (PCs), versus non-hierarchical, cooperative arrangements among fishers, such as fishing cooperatives (coops).

The model reveals that initial levels of trust and the diversity among fishers matter for different self-governance arrangements to be established and persist, and should therefore be taken into account when developing better, targeted policies for improved small-scale fisheries governance. Model analysis was particularly helpful to unravel an intriguing interplay between the macro- (the fish stock, the population of fishers, the numbers of coops and PCs), meso- and microlevels (fishers' reliability and loyalty),

investigating how policy responses by social actors affect the transient dynamics of an ecosystem while it moves towards an attractor (Martin, Schlüter, and Blenckner 2020). Agent-based modelling provides as yet largely unexplored opportunities to understand how an SES pathway unfolds over time through emergent feedbacks and resulting path dependencies or shifts in the direction or strength of feedbacks that determine the future development path of the system. Furthermore, agent-based modelling provides exciting opportunities for identifying social-ecological mechanisms (i.e. the human and non-human actors, interactions and causal processes) that generate emergent phenomena, thus contributing to the development of explanations and middle-range theories of SES phenomena (Schlüter et al. 2019).

Another important new direction is the inclusion of more realistic representations of human decision-making, particularly its embeddedness in changing social and biophysical environments (Schlüter et al. 2017; Huber et al. 2018; Schill et al. 2019, Wijermans et al. 2020). Agentbased models can also provide a method for including human behaviour in models of the Earth system, which is an important research frontier in Earth-system science (Müller-Hansen et al. 2017). This will allow better accounting for the diversity of human motivations and behaviours in SES beyond Homo oeconomicus and the implications of these motivations and behaviours for sustainability, e.g. by leading to unexpected outcomes of policies or management.

New methodological directions in support of the use of agent-based modelling to study the dynamics of SES as complex adaptive systems include the combination of social or social-ecological networks with agent-based modelling (Manson et al. 2016; Dobson et al. 2019), the development of multi-level models that incorporate interactions across scales (Lippe et al. 2019) as well as hybrid models that combine different modelling approaches, such as a dynamical systems representation of an ecosystem with an agent-based representation of human and societal interactions with the ecosystem (Martin and Schlüter 2015). New methodological developments regarding human behaviour include the combination of agent-based models with behavioural experiments (Janssen and Baggio 2016; Schill et al. 2016) and novel formalisations of social science theories, and empirical evidence of the diversity of human behaviour in agent-based models (Wijermans et al. 2020). 
which would have been impossible to study empirically. The community-level patterns of fishers' reliability and loyalty influence the cheating behaviour of individual fishers and ultimately the resulting organisational membership at the mesolevel. The survival of an organisation at the mesolevel, however, was also influenced by the state of the fish population, which resulted from the harvesting activities of all existing PCs and coops in the community at the macrolevel. Finally, the organisational membership also influenced the macrolevel patterns that determine the predominance of either PCs or coops in a community. It is the interplay among these three levels that explains the dominance of PCs or coops at the macrolevel.

In Figure 28.2, each box represents an activity that is a stylised representation of observations from fisheries in north-west Mexico, where the different types of self-governance forms have slightly different ways of operating. Cheating is a key activity, which involves fishers selling their catch to a different organisation than the one they belong to. Fish buyers can select their crew and also exit the fishery if their capital is too low, whereas coops will dismiss members and dissolve if overall loyalty or capital is too low.

\section{Key readings}

Crooks, A., A. Heppenstall, and N. Malleson. 2018. 'Agent-based Modeling.' In Comprehensive Geographic Information Systems, edited by B. Huang, 218-243. Amsterdam: Elsevier.

Gilbert, G.N. 2008. Agent-based Models. Thousand Oaks: Sage.

Heckbert, S., T. Baynes, and A. Reeson. 2010. 'Agent-based Modeling in Ecological Economics.' Annals of the New York Academy of Sciences 1185(1): 39-53. doi:10.1111/j.1749-6632.2009.05286.x.

Janssen, M. 2020. Introduction to Agent-based Modeling. https://intro2abm.com.

Railsback, S.F., and V. Grimm. 2012. Agent-based and Individual-based Modeling - A Practical Introduction. Princeton: Princeton University Press. www.railsback-grimm-abm-book.com.

\section{Acknowledgements}

Maja Schlüter received support from the European Research Council (ERC) under the European Union's Horizon 2020 research and innovation programme (grant agreement no. 682472 - MUSES). Emilie Lindkvist was funded by the Swedish Research Council (Dnr 2018-05862) and the US NSF Coupled Natural and Human Systems Program (DEB1632648). Gary Polhill's work is funded by the Scottish Government, Horizon 2020 and the Research Council of Norway.

\section{References}

Arthur, W.B., S. Durlauf, and D.A. Lane. 1997. 'Process and Emergence in the Economy.' In The Economy as an Evolving Complex System II, edited by W.B. Arthur, S. Durlauf, and D.A. Lane, 14. Reading: Addison-Wesley. http://tuvalu.santafe.edu/ wbarthur/Papers/ADL_Intro.pdf.

Basurto, X., A. Bennett, E. Lindkvist, and M. Schlüter. 2020. 'Governing the Commons beyond Harvesting: An Empirical Illustration from Fishing.' PLoS ONE 15(4): e0231575. doi:10.1371/journal. pone. 0231575 .

Bert, F.E., G.P. Podestá, S.L. Rovere, Á.N. Menéndez, M. North, E. Tatara, C.E. Laciana, E. Weber, and F.R. Toranzo. 2011. 'An Agent Based Model to Simulate Structural and Land Use Changes in Agricultural Systems of the Argentine Pampas.' Ecological Modelling 222(19): 3486-3499. doi:10.1016/j.ecolmodel.2011.08.007. 
Bharwani, S. 2006. 'Understanding Complex Behavior and Decision Making Using Ethnographic Knowledge Elicitation Tools (KnETs).' Social Science Computer Review 24(1): 78-105. doi:10.1177/0894439305282346.

Bousquet, F., O. Barreteau, C. Le Page, C. Mullon, and J. Weber. 1999. 'An Environmental Modelling Approach. The Use of Multiagents Simulations.' In Advances in Environmental and Ecological Modelling, edited by F. Blasco and A. Weill, 113-122. Amsterdam: Elsevier.

Bousquet, F., C. Cambier, P. Morand, J. Quensiere, and C.A.P. Mullon. 1993. 'Simulating the Interaction between a Society and a Renewable Resource.' Journal of Biological Systems 1: 199-214.

Bousquet, F., and C. Le Page. 2004. 'Multi-agent Simulations and Ecosystem Management: A Review.' Ecological Modelling 176(3-4): 313-332. doi:10.1016/j.ecolmodel.2004.01.011.

Burgess, M.G., E. Carrella, M. Drexler, R.L. Axtell, R.M. Bailey, J.R. Watson, R.B. Cabral et al. 2020. 'Opportunities for Agent-based Modelling in Human Dimensions of Fisheries.' Fish and Fisheries. doi:10.1111/faf.12447.

Carpenter, S.R., and W.A. Brock. 2004. 'Spatial Complexity, Resilience, and Policy Diversity: Fishing on Lake-rich Landscapes.' Ecology and Society 9(1): 8.

Castella, J.C., T.N. Trung, and S. Boissau. 2005. 'Participatory Simulation of Land-use Changes in the Northern Mountains of Vietnam: The Combined Use of an Agent-based Model, a Role-playing Game, and a Geographic Information System.' Ecology and Society 10(1): 27. doi:10.5751/ ES-01328-100127.

Castilla-Rho, J.C., R. Rojas, M.S. Andersen, C. Holley, and G. Mariethoz. 2017. 'Social Tipping Points in Global Groundwater Management.' Nature Human Behaviour 1(9): 640-649. doi:10.1038/ s41562-017-0181-7.

Crooks, A., A. Heppenstall, and N. Malleson. 2018. 'Agent-based Modeling.' In Comprehensive Geographic Information Systems, edited by B. Huang, 218-243. Amsterdam: Elsevier.

Dobson, A.D.M., E. de Lange, A. Keane, H. Ibbett, and E.J. Milner-Gulland. 2019. 'Integrating Models of Human Behaviour between the Individual and Population Levels to Inform Conservation Interventions.' Philosophical Transactions of the Royal Society B: Biological Sciences 374(1781). doi:10.1098/rstb.2018.0053.

Dressler, G., J. Groeneveld, C.M. Buchmann, C. Guo, N. Hase, J. Thober, K. Frank, and B. Müller. 2018. 'Implications of Behavioral Change for the Resilience of Pastoral Systems - Lessons from an Agent-based Model.' Ecological Complexity. doi:10.1016/j.ecocom.2018.06.002.

Edmonds, B., V. Grimm, R. Meyer, C. Montañola, P. Ormerod, H. Root, and F. Squazzoni. 2019. 'Different Modelling Purposes.' Journal of Artificial Societies and Social Simulation 22(3): 30.

Epstein, J.M. 2006. Growing Artificial Societies: Social Science from the Bottom Up. Princeton: Princeton University Press.

Evans, T.P., and H. Kelley. 2008. 'Assessing the Transition from Deforestation to Forest Regrowth with an Agent-based Model of Land Cover Change for South-central Indiana (USA).' Geoforum, Conversations Across the Divide 39(2): 819-832. doi:10.1016/j.geoforum.2007.03.010.

Filatova, T., J.G. Polhill, and S. van Ewijk. 2016. 'Regime Shifts in Coupled Socio-environmental Systems: Review of Modelling Challenges and Approaches.' Environmental Modelling E Software 75: 333-347. doi:10.1016/j.envsoft.2015.04.003.

Forrester, J., R. Greaves, H. Noble, and R. Taylor. 2014. 'Modeling Social-Ecological Problems in Coastal Ecosystems: A Case Study.' Complexity 19(6): 73-82. doi:10.1002/cplx.21524.

Gimona, A., and J.G. Polhill. 2011. 'Exploring Robustness of Biodiversity Policy with a Coupled Metacommunity and Agent-based Model.' Journal of Land Use Science 6(2/3): 175-193.

Gotts, N.M., G.A.K. van Voorn, J.G. Polhill, E. de Jong, B. Edmonds, G.J. Hofstede, and R. Meyer. 2018. 'Agent-based Modelling of Socio-Ecological Systems: Models, Projects and Ontologies.' Ecological Complexity. doi:10.1016/j.ecocom.2018.07.007.

Grêt-Regamey, A., S.H. Huber, and R. Huber. 2019. 'Actors' Diversity and the Resilience of Social-Ecological Systems to Global Change.' Nature Sustainability 2(4): 290-297. doi:10.1038/ s41893-019-0236-z.

Grimm, V., U. Berger, F. Bastiansen, S. Eliassen, V. Ginot, J. Giske, J. Goss-Custard et al. 2006. 'A Standard Protocol for Describing Individual-based and Agent-based Models.' Ecological Modelling 198(1-2): 115-126.

Gurung, T.R., F. Bousquet, and G. Trébuil. 2006. 'Companion Modeling, Conflict Resolution, and Institution Building: Sharing Irrigation Water in the Lingmuteychu Watershed, Bhutan.' Ecology and Society 11(2): 36. 
Gutierrez, N.L., P. Halmay, R. Hilborn, A.E. Punt, and S. Schroeter. 2017. 'Exploring Benefits of Spatial Cooperative Harvesting in a Sea Urchin Fishery: An Agent-based Approach.' Ecosphere 8(7): e01829. doi:10.1002/ecs2.1829.

Happe, K., K. Kellermann, and A. Balmann. 2006. 'Agent-based Analysis of Agricultural Policies: An Illustration of the Agricultural Policy Simulator AgriPoliS, its Adaptation and Behavior.' Ecology and Society 11(1): 49. doi:10.5751/ES-01741-110149.

Hare, M., and P. Deadman. 2004. 'Further towards a Taxonomy of Agent-based Simulation Models in Environmental Management.' Mathematics and Computers in Simulation 64: 25-40.

Heckbert, S. 2013. 'MayaSim: An Agent-based Model of the Ancient Maya Social-Ecological System.' Journal of Artificial Societies and Social Simulation 16(4). doi:10.18564/jasss.2305.

Holtz, G., F. Alkemade, F. de Haan, J. Köhler, E. Trutnevyte, T. Luthe, J. Halbe et al. 2015. 'Prospects of Modelling Societal Transitions: Position Paper of an Emerging Community.' Environmental Innovation and Societal Transitions 17: 41-58. doi:10.1016/j.eist.2015.05.006.

Huber, R., M. Bakker, A. Balmann, T. Berger, M. Bithell, C. Brown, A. Grêt-Regamey et al. 2018. 'Representation of Decision-making in European Agricultural Agent-based Models.' Agricultural Systems 167: 143-160. doi:10.1016/j.agsy.2018.09.007.

Janssen, M.A. 2009. 'Understanding Artificial Anasazi.' http://jasss.soc.surrey.ac.uk/12/4/13.html.

Janssen, M. 2020. Introduction to Agent-based Modeling. https://intro2abm.com.

Janssen, M.A., and J.A. Baggio. 2016. 'Using Agent-based Models to Compare Behavioral Theories on Experimental Data: Application for Irrigation Games.' Journal of Environmental Psychology 46: 106-115. doi:10.1016/j.jenvp.2016.04.003.

Janssen, M.A., and E. Ostrom. 2006. 'Empirically Based, Agent-based Models.' Ecology and Society 11(2): 37.

Klein, E.S., M.R. Barbier, and J.R. Watson. 2017. 'The Dual Impact of Ecology and Management on Social Incentives in Marine Common-pool Resource Systems.' Royal Society Open Science 4(8): 170740. doi:10.1098/rsos.170740.

Köhler, J., F. de Haan, G. Holtz, K. Kubeczko, E. Moallemi, G. Papachristos, and E. Chappin. 2018. 'Modelling Sustainability Transitions: An Assessment of Approaches and Challenges.' Journal of Artificial Societies and Social Simulation 21(1): 8.

Kravari, K., and N. Bassiliades. 2015. 'A Survey of Agent Platforms.' Journal of Artificial Societies and Social Simulation 18(1): 11.

Kremmydas, D., I.N. Athanasiadis, and S. Rozakis. 2018. 'A Review of Agent Based Modeling for Agricultural Policy Evaluation.’ Agricultural Systems 164: 95-106. doi:10.1016/j.agsy.2018.03.010.

Lansing, J.S., and J.N. Kremer. 1993. 'Emergent Properties of Balinese Water Temple Networks: Coadaptation on a Rugged Fitness Landscape.' American Anthropologist 95(1): 97-114. doi:10.1525/ aa.1993.95.1.02a00050.

Lee, J-S., T. Filatova, A. Ligmann-Zielinska, B. Hassani-Mahmooei, F. Stonedahl, I. Lorscheid, A. Voinov, Gary Polhill, Z. Sun, and D.C. Parker. 2015. 'The Complexities of Agent-based Modeling Output Analysis.' Journal of Artificial Societies and Social Simulation 18(4). doi:10.18564/jasss.2897.

Lindkvist, E., X. Basurto, and M. Schlüter. 2017. 'Micro-level Explanations for Emergent Patterns of Self-governance Arrangements in Small-scale Fisheries - A Modeling Approach.' PloS ONE 12(4): e0175532.

Lindkvist, E., N. Wijermans, T.M. Daw, B. Gonzalez-Mon, A. Giron-Nava, A.F. Johnson, I. van Putten, Xavier Basurto, and Maja Schlüter. 2020. 'Navigating Complexities: Agent-based Modeling to Support Research, Governance, and Management in Small-scale Fisheries.' Frontiers in Marine Science 6. doi:10.3389/fmars.2019.00733.

Lippe, M., M. Bithell, N. Gotts, D. Natalini, P. Barbrook-Johnson, C. Giupponi, M. Hallier et al. 2019. 'Using Agent-based Modelling to Simulate Social-Ecological Systems across Scales.' GeoInformatica. doi:10.1007/s10707-018-00337-8.

Lorscheid, I., B-O. Heine, and M. Meyer. 2012. 'Opening the "Black Box” of Simulations: Increased Transparency and Effective Communication through the Systematic Design of Experiments.' Computational and Mathematical Organization Theory 18(1): 22-62. doi:10.1007/s10588-011-9097-3.

Manson, S.M., N.R. Jordan, K.C. Nelson, and R.F. Brummel. 2016. 'Modeling the Effect of Social Networks on Adoption of Multifunctional Agriculture.' Environmental Modelling \& Software 75: 388-401. doi:10.1016/j.envsoft.2014.09.015.

Martin, R., and M. Schlüter. 2015. 'Combining System Dynamics and Agent-based Modeling to Analyze Social-Ecological Interactions - An Example from Modeling Restoration of a Shallow Lake.' Frontiers in Environmental Science 3. doi:10.3389/fenvs.2015.00066. 
Martin, R., M. Schlüter, and T. Blenckner. 2020. 'The Importance of Transient Social Dynamics for Restoring Ecosystems beyond Ecological Tipping Points.' Proceedings of the National Academy of Sciences 117(5): 2717-2722. doi:10.1073/pnas.1817154117.

Martin, R., and S.A. Thomas. 2016. 'Analyzing Regime Shifts in Agent-based Models with Equation-free Analysis.' http://scholarsarchive.byu.edu/iemssconference/2016/Stream-B/54.

Melbourne-Thomas, J., C.R. Johnson, P. Perez, J. Eustache, E.A. Fulton, and D. Cleland. 2011. 'Coupling Biophysical and Socioeconomic Models for Coral Reef Systems in Quintana Roo, Mexican Caribbean.' Ecology and Society 16(3): 23. doi:10.5751/ES-04208-160323.

Müller, B., F. Bohn, G. Dreßler, J. Groeneveld, C. Klassert, R. Martin, M. Schlüter, J. Schulze, H. Weise, and N. Schwarz. 2013. 'Describing Human Decisions in Agent-based Models - ODD + D, an Extension of the ODD Protocol.' Environmental Modelling E Software 48: 37-48. doi:10.1016/j. envsoft.2013.06.003.

Müller-Hansen, F., M. Schlüter, M. Mäs, R. Hegselmann, J.F. Donges, J.J. Kolb, K. Thonicke, and J. Heitzig. 2017. 'How to Represent Human Behavior and Decision Making in Earth System Models? A Guide to Techniques and Approaches.' Earth Systems Dynamics Discussions, 1-53.

Parker, D.C., and V. Meretsky. 2004. 'Measuring Pattern Outcomes in an Agent-based Model of Edge-effect Externalities Using Spatial Metrics.' Agriculture, Ecosystems \& Environment 101(2-3): 233-250. doi:10.1016/j.agee.2003.09.007.

Plank, M.J., J. Kolding, R. Law, H.D. Gerritsen, and D. Reid. 2017. 'Balanced Harvesting Can Emerge from Fishing Decisions by Individual Fishers in a Small-scale Fishery.' Fish and Fisheries 18(2): 212-225. doi:10.1111/faf.12172.

Polhill, J.G., T. Filatova, M. Schlüter, and A. Voinov. 2016. 'Modelling Systemic Change in Coupled Socio-environmental Systems.' Environmental Modelling E Software 75: 318-332. doi:10.1016/j. envsoft.2015.10.017.

Polhill, J.G., A. Gimona, and N.M. Gotts. 2013. 'Nonlinearities in Biodiversity Incentive Schemes: A Study Using an Integrated Agent-based and Metacommunity Model.' Environmental Modelling E Software, Thematic Issue 45: 74-91. doi:10.1016/j.envsoft.2012.11.011.

Railsback, S.F., and V. Grimm. 2012. Agent-based and Individual-based Modeling - A Practical Introduction. Princeton: Princeton University Press. www.railsback-grimm-abm-book.com.

Sakoda, J.M. 1971. 'The Checkerboard Model of Social Interaction.' The Journal of Mathematical Sociology 1(1): 119-132. doi:10.1080/0022250X.1971.9989791.

Schelling, T.C. 1971. 'Dynamic Models of Segregation.' The Journal of Mathematical Sociology 1(2): 143-186. doi:10.1080/0022250X.1971.9989794.

Schill, C., J.M. Anderies, T. Lindahl, C. Folke, S. Polasky, J.C. Cárdenas, A-S. Crépin, M.A. Janssen, J. Norberg, and M. Schlüter. 2019. 'A More Dynamic Understanding of Human Behaviour for the Anthropocene.' Nature Sustainability 2(12): 1075-1082. doi:10.1038/s41893-019-0419-7.

Schill, C., N. Wijermans, M. Schlüter, and T. Lindahl. 2016. 'Cooperation Is Not Enough - Exploring Social-Ecological Micro-foundations for Sustainable Common-pool Resource Use.' PLoS ONE 11(8): e0157796. doi:10.1371/journal.pone.0157796.

Schlüter, M., A. Baeza, G. Dressler, K. Frank, J. Groeneveld, W. Jager, M.A. Janssen et al. 2017. 'A Framework for Mapping and Comparing Behavioural Theories in Models of Social-Ecological Systems.' Ecological Economics 131: 21-35. doi:10.1016/j.ecolecon.2016.08.008.

Schlüter, M., J. Hinkel, P.W.G. Bots, and R. Arlinghaus. 2014. 'Application of the SES Framework for Model-based Analysis of the Dynamics of Social-Ecological Systems.' Ecology and Society 19(1): 36. doi:10.5751/ES-05782-190136.

Schlüter, M., B. Müller, and K. Frank. 2019. 'The Potential of Models and Modeling for SocialEcological Systems Research: The Reference Frame ModSES.' Ecology and Society 24(1): 31. doi:10.5751/ES-10716-240131.

Schlüter, M., K. Orach, E. Lindkvist, R. Martin, N. Wijermans, Ö. Bodin, and W.J. Boonstra. 2019. 'Toward a Methodology for Explaining and Theorizing about Social-Ecological Phenomena.' Current Opinion in Environmental Sustainability 39: 44-53. doi:10.1016/j.cosust.2019.06.011.

Schlüter, M., A. Tavoni, and S. Levin. 2016. 'Robustness of Norm-driven Cooperation in the Commons.' Proceedings of the Royal Society B: Biological Sciences 283(1822): 20152431. doi:10.1098/ rspb.2015.2431.

Schmolke, A., P. Thorbek, D.L. DeAngelis, and V. Grimm. 2010. 'Ecological Models Supporting Environmental Decision Making: A Strategy for the Future.' Trends in Ecology \& Evolution 25(8): 479-486. doi:10.1016/j.tree.2010.05.001. 
Schulze, J., B. Müller, J. Groeneveld, and V. Grimm. 2017. 'Agent-based Modelling of Social-Ecological Systems: Achievements, Challenges, and a Way Forward.' Journal of Artificial Societies and Social Simulation 20(2). doi:10.18564/jasss.3423.

Smajgl, A., and O. Barreteau. 2014. Empirical Agent-based Modelling - Challenges and Solutions: Volume 1, The Characterisation and Parameterisation of Empirical Agent-based Models. New York: Springer. doi:10.1007/978-1-4614-6134-0_1.

Smajgl, A., and E. Bohensky. 2011. 'Behaviour and Space in Agent-based Modelling: Poverty Patterns in East Kalimantan, Indonesia.' Environmental Modelling \& Software. doi:10.1016/j.envsoft.2011.10.014.

Smajgl, A., D.G. Brown, D. Valbuena, and M.G.A. Huigen. 2011. 'Empirical Characterisation of Agent Behaviours in Socio-Ecological Systems.' Environmental Modelling \& Software 26(7): 837-844. doi:10.1016/j.envsoft.2011.02.011.

Squazzoni, F. 2010. 'The Impact of Agent-based Models in the Social Sciences after 15 Years of Incursions.' History of Economic Ideas 18: 197-233.

Sun, Z., and D. Müller. 2013. 'A Framework for Modeling Payments for Ecosystem Services with Agent-based Models, Bayesian Belief Networks and Opinion Dynamics Models.' Environmental Modelling \& Software 45: 15-28. doi:10.1016/j.envsoft.2012.06.007.

Thiele, J.C., W. Kurth, and V. Grimm. 2014. 'Facilitating Parameter Estimation and Sensitivity Analysis of Agent-based Models: A Cookbook Using NetLogo and R.' Journal of Artificial Societies and Social Simulation 17(3): 11.

Thomas, S.A., D.J.B. Lloyd, and A.C. Skeldon. 2016. 'Equation-free Analysis of Agent-based Models and Systematic Parameter Determination.' Physica A: Statistical Mechanics and Its Applications 464: 27-53. doi:10.1016/j.physa.2016.07.043.

Villamor, G.B., Q.B. Le, U. Djanibekov, M. van Noordwijk, and P.L.G. Vlek. 2014. 'Biodiversity in Rubber Agroforests, Carbon Emissions, and Rural Livelihoods: An Agent-based Model of Landuse Dynamics in Lowland Sumatra.' Environmental Modelling \& Software 61: 151-165. doi:10.1016/j. envsoft.2014.07.013.

Wijermans, N., W.J. Boonstra, K. Orach, J. Hentati-Sundberg, and M. Schlüter. 2020. 'Behavioural Diversity in Fishing - Towards a Next Generation of Fishery Models.' Fish and Fisheries 21(5): 872-890. doi:10.1111/faf.12466.

Wilson, J., L. Yan, and C. Wilson. 2007. 'The Precursors of Governance in the Maine Lobster Fishery.' Proceedings of the National Academy of Sciences 104(39): 15212-15217.

Worrapimphong, K., N. Gajaseni, C. Lee Page, and F. Bousquet. 2010. 'A Companion Modeling Approach Applied to Fishery Management.' Environmental Modelling \& Software 25(11): 1334-1344. doi:10.1016/j.envsoft.2010.03.012. 